vibration exposure was not above the Swedish threshold limit of $5 \mathrm{~m} / \mathrm{s}^{2}$, nearly $37 \%$ of those surveyed showed signs of carpal tunnel syndrome (CTS). Analysis of the biological markers in the blood samples will be performed soon.

Conclusion This study shows that health effects from exposure to hand-arm vibration are common in the study group even if the vibration exposure is below the Swedish occupational threshold limit of $5 \mathrm{~m} / \mathrm{s}^{2}$.

\section{OCCUPATIONAL DISEASES IN SELF-EMPLOYED WORKERS}

${ }^{1} \mathrm{M}$ Luwel, ${ }^{2,3}$ S Keirsbilck*, 2,4B Nemery. ${ }^{1}$ SPMT-ARISTA, External Service for Prevention and Protection at Work, Brussels, Belgium; ${ }^{2}$ Clinic for occupational and environmental medicine, University Hospital Gasthuisberg, Leuven, Belgium; ${ }^{3}$ IDEWE, External Service for Prevention and Protection at Work, Heverlee, Belgium; ${ }^{4}$ Environment and Health, Department of Public Health and Primary Care, K.U.Leuven, Leuven, Belgium

\subsection{6/oemed-2018-ICOHabstracts. 1086}

Introduction Even in countries with a well-developed occupational health legislation and infrastructure, self-employed workers generally fall outside the scope of the legislation and services that are intended to prevent accidents and disease at work. In curative medicine, little attention is paid to possible occupational causes of medical conditions.

Yet, self-employed people also run occupational health risks in agriculture, crafts, or service professions. The burden of occupational disease among self-employed workers is not known.

Methods A retrospective study was conducted on records of all currently self-employed workers who were referred tot the outpatient clinic dedicated to occupational and environmental health within the division of pneumology of the University Hospitals of Leuven during the period 2000-2014. Their main demographic, occupational and medical characteristics were compared to those of salaried employees seen during the same period.

Results 150 self-employed workers were identified. They represent 5\% of all consultations during this period. $80 \%$ were men. $91 \%$ had active working age. $70 \%$ worked as selfemployed throughout their careers, 30\% had also worked as salaried worker in the past. The main sectors were construction (31\%), food (12\%), agriculture (11\%) and beauty care (11\%). 73\% had respiratory disease with asthma as the most common diagnosis $(n=49)$. The suspected causative agents were synthetic chemicals $(n=52)$, biological agents $(n=42)$ and mineral substances $(n=33)$. Subpopulations of bakers, painters and hairdressers had non-significant different characteristics compared to their salaried colleagues, except for age in hairdressers.

Conclusion Self-employed workers may suffer from occupational respiratory and non-respiratory diseases. Although the evidence is largely anecdotal, it appears that the severity at clinical presentation is higher in self-employed persons than in salaried employees. Although the socio-economic consequences of occupational disease are often dramatic for most workers, it appears that this is even more the case for self-employed persons.
1312 THE RELATIONSHIP BETWEEN THE POST-TRAUMATIC STRESS SYNDROME AND THE OCCUPATIONAL STRESS AMONG THE FIREFIGHTERS IN KOREA

${ }^{1}$ A Ram Kim*, ${ }^{2}$ Joo Hyun Sung, ${ }^{1}$ Seong Woo Cho, ${ }^{3}$ Kyoung Sook Jeong, ${ }^{3}$ Yeon-Soon Ahn, ${ }^{1}$ Chang Sun Sim. ${ }^{1}$ Department of Occupational and Environmental Medicine, Ulsan University Hospital, University of Ulsan College of Medicine, Ulsan, Republic of Korea; ${ }^{2}$ Department of Occupational and Environmental Medicine, Gyeongsang National University Changwon Hospital, Gyeongsang National University School of Medicine, Changwon, Republic of Korea; ${ }^{3}$ Department of Occupational and Environmental Medicine, Dongguk University Ilsan Hospital, Goyang, Republic of Korea

\subsection{6/oemed-2018-ICOHabstracts. 1087}

Introduction Traumatic stress like experience in witnessing a suicide or accidents can cause post-traumatic stress disorder (PTSD). Firefighters are exposed to traumatic stresses due to their professional nature. It is known that dealing with extra stress after the event can be a risk factor in development of the disease. Thus, we aim to study to see whether occupational stress can act as a risk factor in development of PTSD. Methods 310 among total 315 professional firefighters were given written informed consents and answered self -reported questionnaires. Impact of Event Scale-Revision (IES-R), Life Event Checklist (LEC) and Korean Occupational Stress Scale (KOSS) questionnaires were used to assess the PTSD and determine the level of occupational stress. SPSS 21.0 was used for all statistical analysis.

Results According to the IES-R questionnaire, 75 out of 310 subjects $(24.2 \%)$ were in risk of developing PTSD. The LEC score which is designed to screen one's experience of potentially traumatic events was significantly high in the PTSD risk group compared to no risk group $(p=0.008)$. Total KOSS score of PTSD risk group $(49.21 \pm 10.90)$ was also significantly higher than that of no risk group $(45.17 \pm 10.86)(\mathrm{p}=0.005)$. Conclusion The prevalence of PTSD was significantly higher in firefighters than general population in several studies, and result of our study also corresponds well. Furthermore we could confirm that the more impact traumatic stress one has experienced in life, the more likely it is to develop PTSD and occupational stress is playing as a risk factor in the development of the disease. By identifying the level of occupational stress and the impact of traumatic event using simple selfreported questionnaires, it would be easier to detect the people who are in risk of developing PTSD and take early medical intervention to prevent the progression of PTSD.

\section{HOW DO OCCUPATIONAL HEALTH PHYSICIANS IN A BELGIAN OCCUPATIONAL HEALTH SERVICE PERCEIVE THEIR CURRENT AND FUTURE ROLE IN RE- INTEGRATION?}

${ }^{1}$ André Kruse*, ${ }^{1,2}$ Philippe Kiss, ${ }^{1,2}$ Marc de Meester. 'Securex Occupational Health Service, Ghent, Belgium; ${ }^{2}$ Department of Public Health, Ghent University, Ghent, Belgium

\subsection{6/oemed-2018-ICOHabstracts. 1088}

Introduction Recently a new legislation on re-integration of employees on long-term sick leave was introduced in Belgium. The purpose is to facilitate return to work of disabled 